\title{
Associations Between MTHFR Polymorphisms and the Risk of Potentially Malignant Oral Disorders
}

\author{
THOMAS SENGHORE ${ }^{1}$, YU-FENG LI ${ }^{2}$, FUNG-CHANG SUNG ${ }^{3}$, MING-HSUI TSAI ${ }^{4}$, \\ CHUN-HUNG HUA ${ }^{4}$, CHIU-SHONG LIU ${ }^{5}$, MIN-FENG HUNG ${ }^{6}$ and CHIH-CHING YEH ${ }^{1,3 *}$ \\ ${ }^{1}$ School of Public Health, College of Public Health, Taipei Medical University, Taipei, Taiwan, R.O.C.; \\ ${ }^{2}$ Graduate Institute of Biostatistics, Departments of ${ }^{3}$ Public Health, and \\ ${ }^{6}$ Health Risk Management, College of Public Health, \\ China Medical University, Taichung, Taiwan, R.O.C.; \\ Departments of ${ }^{4}$ Otolaryngology, and ${ }^{5}$ Family Medicine, \\ China Medical University Hospital, Taichung, Taiwan, R.O.C.
}

\begin{abstract}
Aim: The study aimed to investigate the role of two polymorphisms of methylenetetrahydrofolate reductase (MTHFR), C677T and A1298C, in the risk of potentially malignant oral disorders (PMODs). Materials and Methods: Genotypes of the MTHFR C677T and A1298C polymorphisms were determined using polymerase chain reaction $(P C R)$ and restriction fragment length polymorphism (RFLP) for 224 PMOD cases and 485 agematched controls. Results: The C677T T allele-carrying genotypes were significantly associated with a decreased risk of PMODs [odds ratio $(O R)=0.62,95 \%$ confidence interval $(C I)=0.44-0.86]$. Haplotype analysis also indicated that the 677T/1298A haplotype was associated with a decreased risk of PMODs (OR=0.56, 95\%CI=0.40-0.80). No significant interaction was observed between MTHFR polymorphisms and lifestyle factors. Conclusion: Our findings suggest that the T-allele-carrying MTHFR C677T genotype or haplotype may reduce the risk of PMODs. However, these observations require further confirmation using larger samples.
\end{abstract}

Oral carcinoma (OC) remains a significant public health burden, with a high incidence and mortality globally (1). In Taiwan, OC is a leading cause of cancer morbidity and the fourth most-common cause of cancer mortally among men (2). Potentially malignant oral disorders (PMODs) that include leukoplakia, erythroplakia, and submucosal fibrosis,

Correspondence to: Professor Chih-Ching Yeh, Ph.D., MSPH, School of Public Health, Taipei Medical University, $250 \mathrm{Wu}-\mathrm{Hsing}$ Street, Taipei 11031, Taiwan, R.O.C. Tel: 88627361661 ext. 6534, Fax: +88627384831, e-mail: ccyeh@tmu.edu.tw

Key Words: Methylenetetrahydrofolate reductase, potentially malignant oral disorders, genetic polymorphism, Taiwan. have a very high rate of transformation to $\mathrm{OC}$, ranging from 4-13\% depending on the follow-up time and subtype $(3,4)$. Although individuals who have habits such as cigarette smoking, and alcohol or betel nut consumption are at risk for PMOD development, only a small fraction of these individuals actually develop such a disorder, suggesting that genetics may be implicated in the etiology (5).

The methylenetetrahydrofolate reductase (MTHFR) gene encodes a cytoplasmic flavoenzyme that channels the distribution of folate by regulating the balance between cellular methylation and nucleic acid synthesis (6), thus promoting DNA stability. Genetic variations of MTHFR have been found to significantly influence many malignancies, including oral squamous cell carcinoma (7). Two widely studied polymorphisms in MTHFR (C667T and A1298C) were found to have a reduced enzymatic activity (8), which results in substrate accumulation in the MTHFR pathway. This causes a disruption in nucleic acid synthesis and a decrease in the availability of methyl groups for cellular biochemical processes (9). Carriers of the 667T allele have about 35-70\% lower enzymatic activity (10), while the 1298CC genotype has about $40 \%$ lower enzymatic activity than do individuals with the AA wild-type genotype (11).

Given the link between polymorphisms of MTHFR C677T and A1298C with a reduced level of genomic DNA methylation, and the influence of MTHFR C667T and A1298C on the risk of OCs (12), we attempted to investigate the association between MTHFR polymorphisms and the risk of PMODs.

\section{Materials and Methods}

Study population. Participants were recruited from a male penitentiary in Taiwan. Of the estimated 4000 inmates, about $76 \%$ consented and were eligible to participate in the study. Irrespective 
of their eligibility status, all inmates underwent a complete oral examination by two experienced otolaryngologists, as per World Health Organization (WHO) criteria (13). All cases were diagnosed as leukoplakia, erythroplakia, submucous fibrosis, oral cancer, or as having other minor oral conditions. Only cases diagnosed as leukoplakia or submucous fibrosis were included in this analysis. Participants with normal oral screening results were used as controls, matched for age.

All eligible participants provided information on their sociodemographic, lifestyle, and medical history through a detailed structured self-administered questionnaire. Sociodemographic and lifestyle factors included cigarette smoking, alcohol consumption, and betel nut chewing, all of which were categorized into three groups as: non-users, current users (those who had used for more than 1 year), and former users (having stopped using continuously for at least the previous 6 months). Total cigarettes consumed were estimated in pack-years as daily consumption multiplied by the duration (in years). The personal medical history, including family history of first-degree relatives only, was also collected. Height and weight were measured, and the body-mass index (BMI) was calculated as weight $/$ height $^{2}$ $\left(\mathrm{kg} / \mathrm{m}^{2}\right)$. All participants gave their written informed consent to participation after a detailed description of the research purpose, and the study was approved by the China Medical University Ethics Review Community and the Institutional Review Board at China Medical University Hospital (IRB no: DMR96-IRB-085).

Single-nucleotide polymorphism (SNP) selection and genotyping. Two functional SNPs in the MTHFR gene were genotyped in this study. These polymorphisms were reported to affect either the expression or function of their host gene or are associated with a risk of malignancy $(14,15)$.

Genotyping was performed using polymerase chain reaction (PCR) and restriction fragment length polymorphism (RFLP). All PCRs were performed in a 20 - $\mu$ l final volume with $5 \mathrm{pM}$ of each primer, $50 \mathrm{ng}$ genomic DNA, $1.5 \mathrm{mM} \mathrm{MgCl} 2,200 \mu \mathrm{M}$ dNTPs, and 1.0 units of Taq DNA polymerase in buffer provided by the manufacturer (Fermentas, Glen Burnie, MD, USA). A Mastercycler gradient thermocycler (Eppendorf, Hamburg, Germany) was used to perform the amplification. Earlier, from buffer coat cells, genomic DNA was extracted using a DNA extraction kit (Qiagen, Chatsworth, CA, USA).

For the MTHFR C677T (rs1801133) polymorphism, primer sequences used were as follows: 5'-TGA AGG AGA AGG TGT CTG CGG GA-3' (forward primer) and 5'-AGG ACG GTG CGG TGA GAG TG-3' (reverse primer). The PCR amplification procedure consisted of $2 \mathrm{~min}$ of denaturing at $94^{\circ} \mathrm{C}$ followed by 30 cycles of $30 \mathrm{~s}$ at $94^{\circ} \mathrm{C}$ and $30 \mathrm{~s}$ at $72^{\circ} \mathrm{C}$. The 198-bp PCR product was digested in HinfI (New England BioLabs, Baverly, MA, USA): The $\mathrm{T}$ allele was cut into 175-and 23-bp fragments and the $\mathrm{C}$ allele was not digested. In the case of the MTHFR A1298C (rs1801131) polymorphism, the following primers were used: 5'-ATG TGG GGG GAG GAG CTG AC-3' (forward primer) and 5'-GTC TCC CAA CTT ACC CTT CTC CC-3' (reverse primer). The PCR cycling conditions included a 5-min denaturing at $92^{\circ} \mathrm{C}$, then 35 cycles of $60 \mathrm{~s}$ at $92^{\circ} \mathrm{C}$, followed by $30 \mathrm{~s}$ at $60.5^{\circ} \mathrm{C}$ and finally $30 \mathrm{~s}$ at $72^{\circ} \mathrm{C}$. The $241-b p$ PCR product was digested with MboII (Fermentas): The A allele was cut into 204-and 37-bp fragments and the $\mathrm{C}$ allele was not digested. Ten percent of genotype determinations were carried out twice in independent experiments, with $100 \%$ concordance for both SNPs.
Table I. Comparisons of characteristics between cases with potentially malignant oral disorders and healthy controls.

\begin{tabular}{|c|c|c|c|}
\hline Variable ${ }^{a}$ & $\begin{array}{c}\text { Controls } \\
\mathrm{N}=485\end{array}$ & $\begin{array}{c}\text { Cases } \\
\mathrm{N}=224\end{array}$ & $p$-Value ${ }^{\mathrm{c}}$ \\
\hline Mean age (SD), years & $38.1(9.1)$ & $38.8(9.2)$ & 0.403 \\
\hline BMI (SD), $\mathrm{kg} / \mathrm{m}^{2}$ & $23.8(3.0)$ & $24.6(3.7)$ & 0.003 \\
\hline Educational level, n (\%) & & & 0.043 \\
\hline Below elementary school & $80(16.5)$ & $43(19.6)$ & \\
\hline Junior high school & $216(44.6)$ & $113(51.4)$ & \\
\hline Above senior high school & $188(38.8)$ & $64(29.1)$ & \\
\hline Cigarette smoking, n (\%) & & & 0.084 \\
\hline Never & $24(5.0)$ & $5(2.2)$ & \\
\hline Current smoker & $424(87.4)$ & 208 (92.9) & \\
\hline Ex-smoker & 37 (7.6) & $11(4.9)$ & \\
\hline Pack-years of cigarettes ${ }^{\mathrm{b}}, \mathrm{n}(\%)$ & & & 0.315 \\
\hline$\leq 7.5$ & $141(29.1)$ & $51(22.8)$ & \\
\hline $7.6-13.0$ & $115(23.7)$ & $54(24.1)$ & \\
\hline $13.1-20.0$ & $123(25.4)$ & $61(27.2)$ & \\
\hline$>20.1$ & $106(21.9)$ & $58(25.9)$ & \\
\hline Alcohol consumption, $\mathrm{n}(\%)$ & & & 0.699 \\
\hline Never & $175(36.1)$ & $74(33.0)$ & \\
\hline Current drinker & $169(34.9)$ & $84(37.5)$ & \\
\hline Ex-drinker & $141(29.1)$ & $66(29.5)$ & \\
\hline Betel nut chewing, n (\%) & & & 0.024 \\
\hline Never & $166(34.3)$ & $54(24.1)$ & \\
\hline Current chewer & $129(26.7)$ & $69(30.8)$ & \\
\hline Ex-chewer & $189(39.1)$ & $101(45.1)$ & \\
\hline Tea consumption, $\mathrm{n}(\%)$ & & & 0.500 \\
\hline Never & $135(27.9)$ & $57(25.5)$ & \\
\hline Current drinker & $333(68.8)$ & $156(69.6)$ & \\
\hline Ex-drinker & $16(3.3)$ & $11(4.9)$ & \\
\hline Family cancer history, n (\%) & & & 0.737 \\
\hline No & $375(77.5)$ & $171(76.3)$ & \\
\hline Yes & $109(22.5)$ & $53(23.7)$ & \\
\hline
\end{tabular}

SD, Standard deviation; BMI, body-mass index. ${ }^{\text {aNumbers may not sum }}$ to the total number due to missing data. ${ }^{b}$ Quartile pack-years of cigarettes among the controls. 'Student's $t$-test or Chi-square test.

Statistical analysis. Pearson's Chi-squared and Student's $t$-test were used to assess participant characteristics. Hardy-Weinberg equilibrium (HWE) was tested using a goodness-of-fit chi-squared test. The PMOD risk was estimated as odds ratios (ORs) and 95\% confidence intervals (CIs) using a multivariate logistic regression adjusted for educational level, BMI, cigarette smoking (pack-years), alcohol consumption, and betel nut chewing. Common variants were considered as the reference. Based on habit, participants with cigarette smoking status were dichotomized into a single binary variable by the median of 13 pack-years of cigarettes for the controls, with similar multivariate logistic regression models used to examine gene- habit interactions. The same analysis was performed for betel nut chewing and alcohol consumption, stratifying participants into never and ever having chewed betel nut or consumed alcohol. Finally, the haplotypes were constructed, and analyses were performed with the THESIAS program (JAVA version; INSERM U525, Paris, France). All analyses were twosided, and a $p$-value of less than 0.05 was considered statistically 
Senghore et al: MTHFR Polymorphisms and Risk of Potentially Malignant Oral Disorders

Table II. Associations between methylenetetrahydrofolate reductase (MTHFR) polymorphisms and the risk of potentially malignant oral disorders.

\begin{tabular}{|c|c|c|c|c|c|c|c|c|c|c|}
\hline \multirow{2}{*}{$\begin{array}{l}\text { MTHFR } \\
\text { genotype }\end{array}$} & \multirow{2}{*}{$\begin{array}{c}\text { Controls } \\
\mathrm{N}=485 \\
\mathrm{n}(\%)\end{array}$} & \multicolumn{2}{|c|}{ All cases $(\mathrm{N}=224)$} & \multirow[b]{2}{*}{$p$-Value } & \multicolumn{2}{|c|}{ Leukoplakia $(\mathrm{N}=170)$} & \multirow[b]{2}{*}{$p$-Value } & \multicolumn{2}{|c|}{ Submucosal fibrosis $(\mathrm{N}=78)$} & \multirow[b]{2}{*}{$p$-Value } \\
\hline & & $\mathrm{n}(\%)$ & OR $(95 \% \mathrm{CI})^{\mathrm{a}}$ & & $\mathrm{n}(\%)$ & OR $(95 \% \mathrm{CI})^{\mathrm{a}}$ & & $\mathrm{n}(\%)$ & OR $(95 \% \mathrm{CI})^{\mathrm{a}}$ & \\
\hline \multicolumn{11}{|l|}{ C677T } \\
\hline $\mathrm{CC}$ & $256(52.8)$ & $145(64.7)$ & 1.00 & & $107(62.9)$ & 1.00 & & $57(73.1)$ & 1.00 & \\
\hline $\mathrm{CT}$ & $193(39.8)$ & $70(31.3)$ & $0.66(0.47-0.94)$ & 0.022 & $55(32.4)$ & $0.71(0.48-1.05)$ & 0.088 & $20(25.6)$ & $0.48(0.27-0.85)$ & 0.011 \\
\hline $\mathrm{TT}$ & $36(7.4)$ & $9(4.0)$ & $0.36(0.15-0.83)$ & 0.017 & $8(4.7)$ & $0.42(0.17-1.05)$ & 0.063 & $1(1.3)$ & $0.13(0.02-0.96)$ & 0.046 \\
\hline $\mathrm{CC}$ & $256(52.8)$ & $145(64.7)$ & 1.00 & & $107(62.9)$ & 1.00 & & $57(73.1)$ & 1.00 & \\
\hline $\mathrm{CT}+\mathrm{TT}$ & $229(47.2)$ & $79(36.3)$ & $0.62(0.44-0.86)$ & 0.005 & $63(37.1)$ & $0.66(0.46-0.97)$ & 0.034 & $21(26.9)$ & $0.42(0.24-0.74)$ & 0.002 \\
\hline \multicolumn{11}{|l|}{ A1298C } \\
\hline AA & $286(59.0)$ & $121(54.0)$ & 1.00 & & $86(50.6)$ & 1.00 & & $47(60.3)$ & 1.00 & \\
\hline $\mathrm{AC}$ & $166(34.2)$ & $88(39.3)$ & $1.26(0.89-1.77)$ & 0.193 & $71(41.8)$ & $1.40(0.96-2.05)$ & 0.080 & $25(32.1)$ & $0.96(0.56-1.64)$ & 0.869 \\
\hline $\mathrm{CC}$ & $33(6.8)$ & $15(6.7)$ & $1.07(0.55-2.07)$ & 0.841 & $13(7.7)$ & $1.28(0.63-2.59)$ & 0.494 & $6(7.7)$ & $1.02(0.39-2.70)$ & 0.967 \\
\hline AA & $286(59.0)$ & $121(54.0)$ & 1.00 & & $86(50.6)$ & 1.00 & & $47(60.3)$ & 1.00 & \\
\hline $\mathrm{AC}+\mathrm{CC}$ & $199(41.0)$ & $103(46.0)$ & $1.23(0.88-1.70)$ & 0.224 & $84(49.4)$ & $1.38(0.96-1.99)$ & 0.080 & $31(39.7)$ & $0.97(0.58-1.61)$ & 0.896 \\
\hline
\end{tabular}

OR, Odds ratio; CI, confidence interval. aAdjusted for educational level, body-mass index, cigarette smoking (pack-years), alcohol consumption, and betel nut chewing.

significant. The SAS Statistical Package (vers. 9.4 for Windows; SAS Institute, Cary, NC, USA) was used for all analyses.

\section{Results}

In total, 224 PMOD cases and 485 cancer-free controls, matched by age were included in the study. Summary statistics of sociodemographic and Iifestyle risk factors are shown in Table I. Statistically significant differences between the cases and controls were only observed in mean BMI, educational level, and betel nut chewing. Cases had a higher mean BMI (24.6 \pm 3.7 vs. $\left.23.8 \pm 3.0 \mathrm{~kg} / \mathrm{m}^{2}, p=0.003\right)$, a lower percentage with above senior secondary school education (29.1 vs. 38.8\%, $p=0.043$ ), and a higher proportion of current and ex-betel nut chewers (30.8 and $45.1 \%$ vs. 26.7 and $39.1 \%$, respectively, $p=0.024$ ) compared to controls.

Distributions of variants in both cases and controls were found to correspond to Hardy-Weinberg equilibrium. Heterozygous carriers of the C667T (OR=0.66, 95\% $\mathrm{Cl}=0.47-0.94, p=0.022)$ and $\mathrm{T} / \mathrm{T}$ homozygous $(\mathrm{OR}=0.36$, $95 \% \mathrm{Cl}=0.15-0.83, p=0.017)$ variants were at an overall decreased risk of PMOD compared to those with wild-type (CC), after adjusting for potential confounders. The C677T T-allele-carrying genotypes were significantly associated with a decreased risk of PMODs $(\mathrm{OR}=0.62,95 \% \mathrm{CI}=0.44$ $0.86, p=0.005)$. Further stratification by PMOD subtypes found similarly significantly reduced risk for submucosal fibrosis $\quad(\mathrm{OR}=0.48,95 \% \quad \mathrm{Cl}=0.27-0.85, \quad p=0.011$ and $\mathrm{OR}=0.13,95 \% \mathrm{Cl}=0.02-0.74, p=0.046$ for $\mathrm{CT}$ and TT, respectively) but not for leukoplakia. A similar analysis was performed on A1298C genotypes, but no significant associations were found in either the overall or stratified analysis (Table II).
Joint effects of gene and lifestyle factors on PMOD risk are shown in Table III. Of the two SNPs evaluated, only the C677T genotype was still significantly associated with PMOD risk in the stratification analysis for all three risky habits; however, this interaction was not statistically significant. In the haplotype analysis, the C677T/A1298C TA haplotype had a significantly lower risk for PMODs overall $(p=0.001)$, leukoplakia $(p=0.018)$, and submucosal fibrosis $(p=0.002)$ compared to the most common CA haplotype (Table IV).

\section{Discussion}

Considering that PMODs have a high transformation rate into OC, understanding the genetic susceptibility for PMOD may provide an opportunity for risk assessment of OC early in the disease course. In this study, we found that carriers of the CT and TT genotypes of C677T had about 1.5-and 2.7-fold, respectively, reduced risk for PMODs compared to those with wild-type $\mathrm{CC}$ genotype. The reduced risk manifested by these genotypes may be due to reduced activity of the corresponding enzymes that causes expanded intracellular pools of 5,10MTHF. The subsequent substrate accumulation increases the availability of thymine, eventually enhancing DNA stability by sequestering 5,10 -MTHF for thymidine synthesis, which lowers the misincorporation of uracil into DNA and reduces global DNA methylation (16).

Many other studies also found protective effects of MTHFR variants on prostate and oral cancer in Asian populations $(12,17)$. Our results are in contrast with those of other studies which indicated an increased risk of OSCC in southeastern Iranians (7), and no association in southern Brazilians (18). These differences in findings might reflect 
Table III. Associations between methylenetetrahydrofolate reductase (MTHFR) genotypes and risk of potentially malignant oral disorders stratified by cigarette smoking, betel nut use and alcohol consumption.

\begin{tabular}{|c|c|c|c|c|c|c|c|c|}
\hline \multirow[t]{2}{*}{$M T H F R$ genotype } & & \multirow{2}{*}{$\begin{array}{c}\text { Controls } \\
(\mathrm{N}=485) \\
\mathrm{n}\end{array}$} & \multicolumn{2}{|c|}{ All cases $(N=224)$} & \multicolumn{2}{|c|}{ Leukoplakia (N=170) } & \multicolumn{2}{|c|}{ Submucosal fibrosis $(\mathrm{N}=78$} \\
\hline & & & $\mathrm{n}$ & OR $(95 \% \mathrm{CI})$ & $\mathrm{n}$ & OR $(95 \% \mathrm{CI})$ & $\mathrm{n}$ & OR $(95 \% \mathrm{CI})$ \\
\hline C677T & Pack-years of cigarettes & & & & & & & \\
\hline $\mathrm{CC}$ & $\leq 13$ & 132 & 64 & 1.00 & 43 & 1.00 & 29 & 1.00 \\
\hline $\mathrm{CT}+\mathrm{TT}$ & $\leq 13$ & 124 & 41 & $0.70(0.43-1.13)^{\mathrm{a}}$ & 31 & $0.80(0.46-1.40)^{\mathrm{a}}$ & 13 & $0.53(0.26-1.11)^{\mathrm{a}}$ \\
\hline $\mathrm{CC}$ & $>13$ & 124 & 81 & 1.00 & 64 & 1.00 & 28 & 1.00 \\
\hline $\mathrm{CT}+\mathrm{TT}$ & $>13$ & 105 & 38 & $0.50(0.31-0.81)^{\mathrm{a} *}$ & 32 & $0.53(0.32-0.89)^{\mathrm{a} *}$ & 8 & $0.29(0.12-0.71)^{\mathrm{a} *}$ \\
\hline$p$ for interaction & & & & 0.33 & & 0.24 & & 0.40 \\
\hline $\mathrm{C} 677 \mathrm{~T}$ & Betel nut chewing & & & & & & & \\
\hline $\mathrm{CC}$ & Never & 75 & 34 & 1.00 & 28 & 1.00 & 7 & 1.00 \\
\hline $\mathrm{CT}+\mathrm{TT}$ & Never & 91 & 20 & $0.45(0.23-0.87)^{\mathrm{b} *}$ & 17 & $0.46(0.23-0.93)^{\mathrm{b} *}$ & 3 & $0.46(0.11-1.99)^{\mathrm{b}}$ \\
\hline $\mathrm{CC}$ & Ever & 181 & 111 & 1.00 & 79 & 1.00 & 50 & 1.00 \\
\hline $\mathrm{CT}+\mathrm{TT}$ & Ever & 137 & 59 & $0.70(0.47-1.04)^{\mathrm{b}}$ & 46 & $0.78(0.50-1.23)^{\mathrm{b}}$ & 18 & $0.46(0.25-0.85)^{\mathrm{b} *}$ \\
\hline$p$ for interaction & & & & 0.23 & & 0.21 & & 0.63 \\
\hline C677T & Alcohol consumption & & & & & & & \\
\hline $\mathrm{CC}$ & Never & 83 & 48 & 1.00 & 40 & 1.00 & 11 & 1.00 \\
\hline $\mathrm{CT}+\mathrm{TT}$ & Never & 92 & 26 & $0.49(0.28-0.89)^{\mathrm{c} *}$ & 20 & $0.47(0.25-0.89)^{\mathrm{c} *}$ & 7 & $0.64(0.23-1.76)^{\mathrm{c}}$ \\
\hline $\mathrm{CC}$ & Ever & 173 & 97 & 1.00 & 67 & 1.00 & 46 & 1.00 \\
\hline $\mathrm{CT}+\mathrm{TT}$ & Ever & 137 & 53 & $0.71(0.47-1.08) \mathrm{c}$ & 43 & $0.84(0.52-1.35)^{\mathrm{c}}$ & 14 & $0.36(0.18-0.72)^{\mathrm{c} *}$ \\
\hline$p$ for interaction & & & & 0.36 & & 0.17 & & 0.39 \\
\hline
\end{tabular}

OR, Odds ratio; CI, confidence interval. aAdjusted for educational level, body-mass index, alcohol consumption, and betel nut chewing. ${ }^{b}$ Adjusted for educational level, body-mass index, alcohol consumption, and cigarette smoking (pack-years). ${ }^{c}$ Adjusted for educational level, body-mass index, cigarette smoking (pack-years) and betel nut chewing. *Significantly different at $p<0.05$.

Table IV. Haplotype analysis of methylenetetrahydrofolate reductase (MTHFR) polymorphisms and risk of potentially malignant oral disorders.

\begin{tabular}{|c|c|c|c|c|c|c|c|c|c|c|}
\hline \multirow{2}{*}{$\begin{array}{l}\text { C677T/ } \\
\text { A1298C }\end{array}$} & \multirow{2}{*}{$\begin{array}{c}\text { Controls } \\
(\mathrm{N}=485) \\
\%\end{array}$} & \multicolumn{2}{|c|}{ All cases $(N=224)$} & \multirow[b]{2}{*}{$p$-Value } & \multicolumn{2}{|c|}{ Leukoplakia $(\mathrm{N}=170)$} & \multirow[b]{2}{*}{$p$-Value } & \multicolumn{2}{|c|}{ Submucosal fibrosis $(\mathrm{N}=78)$} & \multirow[b]{2}{*}{$p$-Value } \\
\hline & & $\%$ & OR $(95 \% \mathrm{CI})^{\mathrm{a}}$ & & $\%$ & OR $(95 \% \mathrm{CI})^{\mathrm{a}}$ & & $\%$ & OR $(95 \% \mathrm{CI})^{\mathrm{a}}$ & \\
\hline $\mathrm{CA}$ & 0.500 & 0.567 & 1.00 & & 0.536 & 1.00 & & 0.631 & 1.00 & \\
\hline $\mathrm{CC}$ & 0.229 & 0.244 & $0.93(0.69-1.26)$ & 0.654 & 0.265 & $1.07(0.78-1.49)$ & 0.668 & 0.232 & $0.80(0.50-1.30)$ & 0.370 \\
\hline TA & 0.261 & 0.167 & $0.56(0.40-0.80)$ & 0.001 & 0.175 & $0.62(0.42-0.92)$ & 0.018 & 0.129 & $0.40(0.23-0.71)$ & 0.002 \\
\hline $\mathrm{TC}$ & 0.011 & 0.022 & $1.69(0.55-5.17)$ & 0.357 & 0.024 & $1.98(0.60-6.51)$ & 0.261 & 0.007 & $0.61(0.06-6.07)$ & 0.674 \\
\hline
\end{tabular}

OR, Odds ratio; CI, confidence interval. aAdjusted for educational level, body-mass index, cigarette smoking (pack-years), alcohol consumption, and betel nut chewing. Among controls, C677T was in weak linkage disequilibrium with A1298C $\left(\mathrm{r}^{2}=0.08, \mathrm{D}^{\prime}=-0.83 ; p<0.0001\right)$.

differences in ethnicity and tumor types, and may be the result of small sample sizes. Other evidence implicates aberrant DNA methylation in promoting tumorigenesis by selective growth and transformation of cells resulting from hypermethylation of tumor-suppressor genes. However, the decreased activity of MTHFR associated with reduced global DNA methylation was proven in mouse models (19).

No significant interactions between Iifestyle factors and the two SNPs with PMOD risk were observed, but those with MTHFR C677T T-allele-carrying genotype possessed a significantly reduced risk for overall PMODs, leukoplakia, and submucosal fibrosis which was modified by smoking.
Our findings are supported by similar studies in Taiwanese $(12,20)$. Evidence suggests that the C677T CC genotype may affect MTHFR activity $(10,11)$, especially in the presence of high folate levels which thereby influence its normal function (21). In the stratified analysis of betel nut and alcohol consumption, those with the T-allele-carrying genotype who never chewed betel nut or consumed alcohol had a little over a 2-fold decreased risk for overall PMODs and leukoplakia compared to their CC genotype counterparts. On the contrary, betel nut and alcohol consumers with C677T C allele-carrying genotypes had significantly reduced risk only for submucosal fibrosis. In the literature, findings 
on alcohol and betel nut consumption modifying the effect on head and neck cancer are mixed. While one found no such effect with alcohol and betel nut use (12), another found an interaction or a decreased association in heavy/ever drinkers (22), and still another found an increased association in heavy drinkers with the CT and TT genotypes (23). Interactions between the C677T SNP and these two environmental factors on PMOD risk may be complicated and not only involve folate but also other factors of the folate metabolic pathway (24). The discrepancy in findings may be attributable to differences in racial origin, lifestyle, and dietary pattern in different populations.

In the haplotype analysis, we found the C677T/A1298C TA haplotype to be associated with a reduced risk for PMODs, suggesting that the $\mathrm{T}$ allele of C677T may play a leading role in the determination of PMOD risk. As previously reported, van der Put et al. found the combined heterozygote of C677T and A1298C to lead to an effect similar to that of the C677T TT genotype (11).

Our study has certain limitations. Firstly, there was a lack of information on dietary folate intake and plasma folate level. Secondly, participants included only males. Finally, the statistical power was low, especially in the stratification analysis. Despite these limitations, to our knowledge, no other study investigated the effects of MTHFR genotypes on PMOD risk. These observations may require further confirmation using larger samples.

\section{Conclusion}

Our findings suggest that the MTHFR 677 genotypes and C677T/A1298C haplotype with T-allele, but not the A1298C polymorphism, may be associated with a significantly reduced risk for PMODs in a Taiwanese population.

\section{Acknowledgements}

The Authors are grateful to study participants.

\section{References}

1 Gupta B, Johnson NW and Kumar N: Global epidemiology of head and neck cancers: A continuing challenge. Oncology 91(1): 13-23, 2016.

2 Chiang C-J, Lo W-C, Yang Y-W, You S-L, Chen C-J and Lai M$\mathrm{S}$ : Incidence and survival of adult cancer patients in Taiwan, 2002-2012. J Formosan Med Assoc 115(12): 13, 2016.

3 Yang PY, Chen YT, Wang YH, Su NY, Yu HC and Chang YC: Malignant transformation of oral submucous fibrosis in Taiwan: A nationwide population-based retrospective cohort study. J Oral Pathol Med 46(10): 1040-1045, 2017.

4 Lyu MY, Guo YS, Li S, Yang D and Hua H: Hospital-based epidemiological and clinical characterisation of the malignant transformation of oral leukoplakia in a Chinese population. Int Dent J 67(4): 252-259, 2017.
5 Paulino YC, Hurwitz EL, Warnakulasuriya S, Gatewood RR, Pierson KD, Tenorio LF, Novotny R, Palafox NA, Wilkens LR and Badowski G: Screening for oral potentially malignant disorders among areca (betel) nut chewers in Guam and Saipan. BMC Oral Health 14: 151, 2014.

6 Fenech M: The role of folic acid and vitamin B12 in genomic stability of human cells. Mutat Res 475(1-2): 57-67, 2001.

7 Miri-Moghaddam E, Saravani S, Garme Y, Khosravi A, Bazi A and Motazedian J: Methylenetetrahydrofolate reductase C677T and $\mathrm{A} 1298 \mathrm{C}$ gene polymorphisms in oral squamous cell carcinoma in South-East Iran. J Oral Pathol Med 45(2): 96$100,2016$.

8 Weisberg I, Tran P, Christensen B, Sibani S and Rozen R: A second genetic polymorphism in methylenetetrahydrofolate reductase $(M T H F R)$ associated with decreased enzyme activity. Mol Genet Metab 64(3): 169-172, 1998.

9 Fenech M: The role of folic acid and vitamin B12 in genomic stability of human cells. Mutat Res 475(1-2): 57-67, 2001.

10 Frosst P, Blom HJ, Milos R, Goyette P, Sheppard CA, Matthews RG, Boers GJ, den Heijer M, Kluijtmans LA, van den Heuvel LP and Rozen R: A candidate genetic risk factor for vascular disease: A common mutation in methylenetetrahydrofolate reductase. Nat Genet 10(1): 111-113, 1995.

11 van der Put NM, Gabreels F, Stevens EM, Smeitink JA, Trijbels FJ, Eskes TK, van den Heuvel LP and Blom HJ: A second common mutation in the methylenetetrahydrofolate reductase gene: An additional risk factor for neural-tube defects? Am J Hum Genet 62(5): 1044-1051, 1998.

12 Tsai CW, Hsu CF, Tsai MH, Tsou YA, Hua CH, Chang WS, Lin $\mathrm{CC}$ and Bau DT: Methylenetetrahydrofolate reductase (MTHFR) genotype, smoking habit, metastasis and oral cancer in Taiwan. Anticancer Res 31(6): 2395-2399, 2011.

13 Warnakulasuriya S, Johnson NW and van der Waal I: Nomenclature and classification of potentially malignant disorders of the oral mucosa. J Oral Pathol Med 36(10): 575$580,2007$.

14 Lievers KJ, Boers GH, Verhoef P, den Heijer M, Kluijtmans LA, van der Put NM, Trijbels FJ and Blom HJ: A second common variant in the methylenetetrahydrofolate reductase (MTHFR) gene and its relationship to MTHFR enzyme activity, homocysteine, and cardiovascular disease risk. J Mol Med 79(9): 522-528, 2001.

15 Guo S, Jiang X, Chen X, Chen L, Li X and Jia Y: The protective effect of methylenetetrahydrofolate reductase C677T polymorphism against prostate cancer risk: Evidence from 23 case-control studies. Gene 565(1): 90-95, 2015.

16 Sohn KJ, Croxford R, Yates Z, Lucock M and Kim YI: Effect of the methylenetetrahydrofolate reductase C677T polymorphism on chemosensitivity of colon and breast cancer cells to 5fluorouracil and methotrexate. J Natl Cancer Inst 96(2): 134-144, 2004.

17 Jia J, Ma Z and Wu S: Positive association between MTHFR C677T polymorphism and oral cancer risk: A meta-analysis. Tumour Biol 35(5): 4943-4948, 2014.

18 Barbosa A, Dos Santos M, de Podesta JR, Gouvea SA, Von Zeidler SV, Louro ID and Cordeiro-Silva $M$ de F: Polymorphisms in methylenetetrahydrofolate reductase and cystathionine beta-synthase in oral cancer - a case-control study in southeastern Brazilians. Braz J Otorhinolaryngol 82(5): 558$566,2016$. 
19 Chen Z, Karaplis AC, Ackerman SL, Pogribny IP, Melnyk S, Lussier-Cacan S, Chen MF, Pai A, John SW, Smith RS, Bottiglieri T, Bagley P, Selhub J, Rudnicki MA, James SJ and Rozen R: Mice deficient in methylenetetrahydrofolate reductase exhibit hyperhomocysteinemia and decreased methylation capacity, with neuropathology and aortic lipid deposition. Hum Mol Genet 10(5): 433-443, 2001.

20 Liu CS, Tsai CW, Hsia TC, Wang RF, Liu CJ, Hang LW, Chiang SY, Wang CH, Tsai RY, Lin CC and Bau DT: Interaction of methylenetetrahydrofolate reductase genotype and smoking habit in Taiwanese lung cancer patients. Cancer Genomics Proteomics 6(6): 325-329, 2009.

21 Chen J, Ma J, Stampfer MJ, Palomeque C, Selhub J and Hunter DJ: Linkage disequilibrium between the $677 \mathrm{C}>\mathrm{T}$ and $1298 \mathrm{~A}>\mathrm{C}$ polymorphisms in human methylenetetrahydrofolate reductase gene and their contributions to risk of colorectal cancer. Pharmacogenetics 12(4): 339-342, 2002.
22 Yang CX, Matsuo K, Ito H, Shinoda M, Hatooka S, Hirose K, Wakai K, Saito T, Suzuki T, Maeda T and Tajima K: Geneenvironment interactions between alcohol drinking and the MTHFR C677T polymorphism impact on esophageal cancer risk: Results of a case-control study in Japan. Carcinogenesis 26(7): 1285-1290, 2005.

23 Zhuo X, Song J, Li D, Wu Y and Zhou Q: MTHFR C677T polymorphism interaction with heavy alcohol consumption increases head and neck carcinoma risk. Sci Rep 5: 10671, 2015.

24 Nazki FH, Sameer AS and Ganaie BA: Folate: Metabolism, genes, polymorphisms and the associated diseases. Gene 533(1): 11-20, 2014.

Received April 19, 2018

Revised May 17, 2018

Accepted May 21, 2018 